\title{
Migração interna de mestres e doutores no Brasil: algumas considerações ${ }^{1}$
}

\section{Internal migration of master and doctoral degree holders in Brazil: some considerations}

\section{Migración interna de másteres y doctores en Brasil: algunas consideraciones}

Sergio Oswaldo de Carvalho Avellar, mestre em Economia Aplicada pela Universidade Federal de Viçosa (UFV), doutorando em Demografia na Universidade de Campinas (Unicamp) e analista de C\&T da Coordenação de Aperfeiçoamento de Pessoal de Nivel Superior (Capes). E-mail: sergio.avellar@capes.gov.br.

\section{Resumo}

A migração interna de mestres e doutores no Brasil é um fenômeno recente, mas que tem se intensificado ao longo das últimas décadas. A ampliação da circulação dessa mão de obra qualificada entre as diversas regiões do País é consequência, principalmente, da desconcentração do Sistema Nacional de Pós-Graduação (SNPG) e também da expansão do ensino superior. A principal atividade econômica empregadora desse grupo populacional (a educação) é vinculada, direta ou indiretamente, à política educacional para o ensino superior. Portanto, para entender esse fenômeno, é necessário compreender como ocorreu a expansão da política (de Estado) educacional ao longo do tempo, seja pela ótica da oferta (criação e expansão dos programas/cursos de pósgraduação), seja pela ótica da demanda (contratação de professores para o ensino superior).

Palavras-chave: Migração Interna. Mestres/Doutores. Circulação de Cérebros. Ensino Superior.

Versão revista e ampliada de Trabalho apresentado no VIII Encontro Nacional Sobre Migrações, GT Migrações - ABEP, realizado em Belo Horizonte - MG nas dependências da UFMG/ FACE/Cedeplar - Brasil, de 23 a 25 de outubro de 2013. Unicamp, Campinas. 


\section{Abstract}

Internal migration of master and doctoral degree holders in Brazil is a recent phenomenon, but it has intensified over the past decades. The expansion of this movement of skilled labor between the various regions of the country is mainly due to the deconcentration of the National System of Graduate Study (SNPG) and also to the expansion of higher education. The main economic activity (Education) employing this population group is linked, directly or indirectly, to educational policy for higher education. Therefore, to understand this phenomenon it is necessary to understand how the expansion of this educational policy (of the State) has occurred over time, either from the supply point of view (creation and expansion of graduate programs/courses) or from the demand side perspective (hiring teachers for higher education).

Keywords: Internal Migration. Masters/Doctors. Brain Circulation. Higher Education.

\section{Resumen}

La migración interna de los másteres y los doctores en Brasil es un fenómeno reciente, pero se ha intensificado a lo largo de las últimas décadas. La expansión de este movimiento de mano de obra calificada entre las distintas regiones del país es, sobre todo, la consecuencia de la descentralización del Sistema Nacional de Pós-Graduação (SNPG), así como la expansión de la educación superior. La principal actividad económica que emplea ese grupo de la población (la educación) está vinculada, directa o indirectamente, a la política educativa para la educación superior. Así que, para entender este fenómeno, es necesario entender cómo se produjo la expansión de esta política (de Estado) para la Educación a través del tiempo, ya sea por el lado de la oferta (creación y expansión de los programas/cursos de posgrado) ya sea por el lado de la óptica de la demanda (contratación de profesores para la educación superior).

Palabras Clave: Migración. Másteres/Doctores. Circulación de Cerebros. Educación Superior. 


\section{Introdução}

O número de mestres e doutores no Brasil, como no restante do mundo, é extremamente diminuto perante o total da população. Ainda assim, esse grupo desempenha papel relevante para o desenvolvimento econômico dos países, pois são pessoas extremamente qualificadas e que têm maior probabilidade de contribuir para o avanço do conhecimento e da tecnologia, variáveis reconhecidas pela literatura econômica como responsáveis pelo crescimento e desenvolvimento de uma nação nos médio e longo prazos.

Para Mukkala (2005), a migração de trabalhadores qualificados é uma das principais fontes de difusão do conhecimento tecnológico, dado que essas pessoas levam consigo um tipo de conhecimento que só pode ser transmitido via contato direto.

O Sistema Nacional de Pós-Graduação (SNPG), desde a sua gênese, tem como funções: a) formar professores competentes que possam atender à expansão quantitativa do ensino superior com elevada qualidade; b) estimular o desenvolvimento da pesquisa científica por meio da preparação adequada de pesquisadores e c) assegurar o treinamento eficaz de técnicos e trabalhadores intelectuais do mais alto padrão, com o intuito de atender às necessidades do desenvolvimento nacional em todos os setores. De acordo com Cunha (1974), as funções do SNPG visam suprir dois grandes mercados. O primeiro é o próprio sistema de ensino superior, em grande expansão quantitativa. O segundo, para os pósgraduados, é constituído pelas agências governamentais e empresas privadas. Além desse fluxo de recursos humanos, há a transferência de tecnologia gerada pelos programas/cursos de pós-graduação, o que pode beneficiar consumidores, empresas e governo.

A contratação de mestres e, especialmente, de doutores pelo setor privado ainda é um movimento incipiente no Brasil. Viotti (2010; 2012) calculou o emprego de mestres e doutores titulados pelo SNPG por natureza jurídica dos estabelecimentos entre os anos de 1996 a 2009 e concluiu que as três esferas da administração pública (federal, estadual e municipal) responderam pelo emprego de $47,1 \%$ e $70,2 \%$, respectivamente, 
enquanto as empresas privadas respondiam por 21,5\% dos empregos para mestres e por $7,6 \%$ dos empregos para doutores.

Por isso, a hipótese deste trabalho é a de que o fluxo migratório desse contingente populacional em direção às regiões Norte e Nordeste tenha se iniciado com a criação e a expansão de cursos de pósgraduação autorizados pelo Ministério da Educação, via Coordenação de Aperfeiçoamento de Pessoal de Nível Superior (Capes). No primeiro momento, ao se instalarem nessas regiões, os cursos de pós-graduação demandam a contratação de professores com título de doutorado ou mestrado provenientes de outras regiões do País. Em um segundo momento, esses programas/cursos atraem estudantes, da localidade ou de fora, para a realização de seus estudos. Ao concluírem a graduação e/ ou a pós-graduação, esses novos profissionais poderão fixar residência na própria região, elevando, assim, a massa crítica local.

Portanto, para se entender o processo migratório, é necessário discutir o fluxo populacional decorrente de uma política educacional de Estado (expansão do SNPG) para as regiões de fronteira (principal) e aquele influenciado pela desconcentração industrial, que levou à instalação de unidades industriais fora das regiões Sul e Sudeste do País ao longo dos últimos anos (secundário).

\section{Objetivos}

Com o objetivo de suprir essa lacuna na literatura acadêmica nacional, este trabalho procura construir as matrizes migratórias (utilizando o quesito de data fixa do Censo 1991 a 2010) de mestres e doutores, bem como calcular o Índice de Eficácia Migratória (IEM) de estados e regiões. Além disso, é apresentado arcabouço teórico adequado para explicar a migração desse grupo populacional.

\section{Metodologia}

Para iniciar este trabalho, procurou-se realizar uma breve revisão bibliográfica sobre a migração de mestres e doutores no Brasil. 
A literatura brasileira sobre o tema é extremamente reduzida, e a maior parte dos trabalhos dedica-se a estudar a migração internacional do grupo populacional em questão. A seguir, são apresentados alguns trabalhos que analisaram a migração interna de mestres e doutores no Brasil.

Sabbadini e Azzoni (2006) apresentaram um estudo empírico sobre a migração interestadual de mestres e doutores no Brasil nas décadas de 80 e 90 e sua correlação com a assimetria entre o desenvolvimento dos estados e regiões brasileiras. Para tanto, eles utilizaram os dados dos Censos de 1991 e 2000 e técnicas econométricas, em um modelo gravitacional, para tentar determinar o padrão espacial de distribuição desse grupo populacional e as variáveis relacionadas a essa migração. Como referencial teórico, optaram pela teoria do Brain Drain (Fuga de Cérebros) para tentar demonstrar que, enquanto alguns estados, especialmente da região Norte, foram beneficiados pelo deslocamento de pessoal qualificado, outros foram prejudicados pela perda de tais trabalhadores.

Guimarães (2002) publicou artigo no qual visava apresentar a origem, o destino, as motivações gerais e os padrões de retorno dos deslocamentos de longo prazo nacionais e internacionais de pesquisadores brasileiros durante a década de 90. Algumas das principais conclusões desse trabalho são: i) o pesquisador no Brasil, na década de 90, migrou visando exercer melhor sua profissão, ii) houve evidências diretas e indiretas de que o fenômeno migratório aumentou durante o período de análise.

Pode-se concluir que a literatura nacional sobre a migração interna de mestres e doutores é muito escassa, sendo necessários um aprofundamento teórico e a apresentação de indicadores quantitativos das diversas bases de dados disponiveis (Censo, RAIS, PNAD etc.), com o intuito de auxiliar no aperfeiçoamento da política pública na área de educação superior.

Apesar das contribuições que os trabalhos citados deram para a área de migração, acredita o autor que a mobilidade de mestres e doutores é dependente - e também a ela condicionada - da expansão do 
Sistema Nacional de Pós-Graduação (oferta) e da expansão dos postos de trabalho no setor educacional e em empresas públicas e privadas.

A migração interna de mestres e doutores está profundamente associada à criação dos primeiros cursos / programas de pós-graduação, na década de 60 do século passado. De acordo com Cury (2005), havia a urgência de se promover a consolidação dos cursos de pós-graduação, tendo em vista a necessidade do País de formar seus próprios cientistas, professores e técnicos, que há muito recorriam às universidades estrangeiras.

A migração de mestres e doutores dentro do Brasil (modalidade) pode ser inserida em um arcabouço teórico proposto por Baeninger (2012). Para a autora, na reconstrução histórica do fenômeno migratório, pode-se encontrar elementos que permitem acompanhar o deslanchar de processos posteriores. Nas condições sociais contemporâneas, a complexidade, a importância, as novas rotas e direções coexistem com processos migratórios antigos (internos e internacionais), que se redefinem na composição de um movimento mais amplo de transformação social. A reconstrução histórica desse fenômeno, com o aporte teórico histórico-estrutural, e a identificação de tipos ideais na migração são aportes que auxiliam na análise de contextos, etapas, seletividade, subtipos (denominados de modalidade migratória) e comparações, em meio aos diversificados movimentos migratórios experimentados pela sociedade brasileira.

Na década de 70, o tipo migratório que prevalecia era o ruralurbano; já a partir da década de 80, um novo tipo migratório passa a prevalecer: o urbano-urbano. Ainda assim, a modalidade migratória (migração interna de mestres e doutores) está presente em ambos os períodos.

Essa modalidade migratória vem passando por transformações ao longo do tempo (aumento do seu volume e intensidade), refletindo o crescimento e a maturação do ensino superior brasileiro (graduação e pós-graduação). Além disso, as migrações intrarregionais passam a ser predominantes nas regiões Norte e Nordeste, seguindo uma tendência que já prevalecia em outras regiões, especialmente o Sudeste e o Sul do País. 
O referencial teórico utilizado para analisar essa modalidade migratória interna de mestres e doutores nos anos 90 e na primeira década do século XXI é um modelo sociológico desenvolvido por Portes (1976), para analisar a migração de médicos argentinos para os Estados Unidos da América, e a teoria da Circulação de Cérebros (Brain Circulation).

Na década de 70, o principal aporte teórico utilizado para analisar a migração de mão de obra qualificada entre países era o Brain Drain. Entretanto, a premissa geral dessa teoria não era corroborada pelas diversas estatísticas disponíveis, pois, em muitos casos, vários países desenvolvidos, inclusive os que formam o Reino Unido, apresentavam uma migração desse grupo populacional bem superior à de países em desenvolvimento, tanto em termos absolutos, quanto em termos relativos. Em decorrência da deficiência desse aporte teórico, Portes (1976) critica a teoria do Brain Drain e propõe um modelo alternativo.

A primeira premissa desse modelo reconhece que os desequilíbrios entre regiões é uma importante variável para explicar tal migração, ou seja, quanto maior for o desnível entre áreas geográficas, em termos de condição de trabalho, remuneração, status social e qualidade de vida, maior tende a ser a migração dessa mão de obra qualificada.

Porém, sozinha, essa premissa é incapaz de explicar tal fenômeno demográfico. Assim, com o objetivo de complementá-la, o autor sugere a análise das variáveis educacionais internas de cada país, bem como das políticas públicas que as norteiam, permitindo ao pesquisador identificar se há um desequilíbrio entre a oferta e a demanda nesse mercado de trabalho. Sumariamente, a segunda proposição procura explicar a migração, analisando o local de origem.

Professional emigration is a consequence of internal structural imbalances between the supply of professionals produced by the educational system of a society and the internal demand for their services. The greater the excess of supply in quantitative and qualitative terms, the greater the emigration (PORTES, 1976, p. 500)

Mesmo com a segunda proposição, esse modelo não é capaz de explicar por que há essa migração, ou melhor, por que tantos não 
migram. Para responder a essa questão, é necessário associar as duas macropremissas anteriores a questões motivacionais de cada indivíduo, ou seja, é necessário incluir o aspecto micro ao modelo. Por uma questão de indisponibilidade de dados (entrevistas qualitativas), o presente trabalho será baseado nas duas primeiras premissas, mas pretende-se inserir a terceira delas em trabalhos futuros.

O conceito de circulação de cérebros (Brain Circulation) é uma teoria de migração internacional desenvolvida ao longo da década de 90, que pretendia fazer uma contraposição à teoria da fuga de cérebros (Brain Drain). Para Daugeliene (2009), o Brain Circulation é o resultado da evolução e alteração das teorias do Brain Drain e Brain Gain. Os pesquisadores que analisam esse fenômeno por meio da teoria do Brain Circulation ressaltam que a migração de mão de obra qualificada está cada vez mais global. A prática se caracteriza pelos deslocamentos frequentes dos profissionais, e dela resulta uma constante troca de conhecimento científico entre nações.

A circulação de cérebros é um fenômeno bem-vindo em diferentes países, especialmente aqueles com baixo potencial de desenvolvimento. Porém, existem outros fatores (desenvolvimento das instituições, investimento em P\&D, ampliação da produtividade etc.) que devem ser considerados, além da ampliação da capacidade de indivíduos ou grupos sociais, para que uma região possa entrar em um ciclo de desenvolvimento, conclui Daugeliene (2009).

\section{Resultados e discussão}

O Censo 2010 apresentou como novidade, em seu questionário da amostra, no campo 6.35, a variável "Qual é a espécie de curso mais elevado que concluiu?", com os quadrinhos referentes a "superior de graduação", “mestrado" e “doutorado". Com isso, pode-se calcular, de forma separada, o tamanho da população brasileira de mestres e doutores e sua migração, o que não era possível até o censo anterior. Entretanto, esse novo dado só nos dá a situação educacional desse grupo populacional na última década (fotografia), não sendo possível comparar 
o resultado com as informações disponiveis nos censos anteriores, ou seja, ainda não é possível construir uma série histórica.

Nos censos anteriores a 2010, os níveis mestrado e doutorado eram agrupados. A fim de efetuar uma comparação temporal entre os censos, optou-se por utilizar as variáveis “Qual é o curso mais elevado que frequentou, no qual concluiu pelo menos uma série?” e “Concluiu o curso no qual estudou?" de forma conjunta, para estimar a população nacional de mestres e doutores ao longo do tempo.

Para a elaboração da matriz migratória e seus demais indicadores, optou-se por utilizar o quesito "data fixa” presente nos Censos de 1991 a 2010 por regiões geográficas e por estados.

O Sistema Nacional de Pós-Graduação, visando atender às funções a ele atribuídas por intermédio dos diversos Planos Nacionais de Pós-Graduação (PNPG), tem apresentado robusta taxa de crescimento anual em seus principais indicadores, conforme demonstrado na Tabela 1.

\section{Tabela 1. Taxa de crescimento anual de indicadores selecionados do SNPG - 1991 a 2010}

\begin{tabular}{l|c|c}
\hline \multirow{2}{*}{ Varíaveis/Ano } & \multicolumn{2}{|c}{ Tax Cres SNPG } \\
\cline { 2 - 3 } & $\mathbf{1 9 9 1 - 2 0 0 0}$ & $\mathbf{2 0 0 0 - 2 0 1 0}$ \\
\hline Cursos & 6,1 & 6,8 \\
\hline Alunos matriculados & 6,7 & 6,7 \\
\hline Alunos titulados & 12,6 & 8,9 \\
\hline
\end{tabular}

Fonte: Capes, GeoCapes e PNPG 2011 a 2020. Elaboração do autor.

O resultado desse esforço de construção e expansão do sistema de formação de pós-graduados, ao longo de mais de cinco décadas, é um crescimento em termos absolutos e relativos da população titulada de mestres e doutores no Brasil. Analisando os dados da Tabela 2, é possível observar que, proporcionalmente, a taxa de crescimento da população de mestres e doutores no Brasil se elevou mais do que a população total e a de graduados. Essa mesma tendência é observada em todas as regiões do Brasil, com exceção feita ao Norte, no período 2000-2010. 
Como salienta Guimarães (2002), a desigualdade é o traço mais característico do nosso País, assumindo, talvez, uma de suas situações mais críticas no terreno científico-tecnológico. Muito embora nenhum país exiba uma distribuição territorial homogênea de sua capacidade instalada de pesquisa, tudo indica que, no Brasil, com sua histórica e reiterada tradição de concentrar, essa distribuição seja bem mais desigual do que a observada nos países líderes em pesquisa no mundo, pelo menos aqueles com dimensão territorial e diversidade cultural comparáveis às nossas.

Essa afirmativa é confirmada pelos dados apresentados na Figura 1. As regiões Sudeste e Sul do País, por concentrarem a maior parte dos programas de pós-graduação (oferta) pertencentes ao SNPG (69,1\% em 2010) e, ao mesmo tempo, por terem um amplo sistema universitário, grande burocracia estatal e um setor industrial que investe em P\&D (demanda), conseguem reter em seus limites geográficos a maior parte da população de mestres e doutores brasileiros. Entretanto, a assimetria entre as regiões tem se reduzido ao longo dos últimos 30 anos. Na década de 80, o quinto quintil (2,56 a 4,2 mestres e doutores por mil habitantes) era composto somente pelos estados de São Paulo e Rio de Janeiro; na década passada, todos os estados do Sudeste e do Sul e mais o Mato Grosso do Sul apresentavam mais alta relação de mestres e doutores por mil habitantes.

A taxa de crescimento apresentada na Tabela 2, apesar de demonstrar uma simetria no crescimento da população de mestres e doutores em todos os estados, nada nos informa sobre sua distribuição absoluta e relativa entre as unidades da Federação.

A distribuição da população de mestres e doutores no Brasil tem uma correlação positiva elevada com a implantação e a expansão do sistema de ensino superior, tanto na pós-graduação (oferta) quanto na graduação (demanda). Como esse sistema apresenta assimetrias muito acentuadas entre regiões e estados do País, a migração interna dessa mão de obra qualificada tende a ser também influenciada ao longo dos anos pela política pública para esse nível educacional. 
A migração de mão de obra qualificada (mestres e doutores) no Brasil tem aumentado, tanto em termos absolutos quanto relativos. No Censo de 1991 (quesito “data fixa"), 18.128 mestres e doutores mudaram de domicílio, o que representou aproximadamente 12\% da população de pós-graduados. Já no Censo de 2000, esse número elevou-se para 38.264 (12,5\% da população total de mestres e doutores). O Censo de 2010 apresentou um novo crescimento: os migrantes com alto nível de qualificação atingiram o volume de 101.421 pessoas.

Esse crescimento mais que proporcional no número de migrantes com mestrado e doutorado em relação à população de mestres e doutores fez com que a participação percentual destes atingisse a cifra de $16,65 \%$ do total da população brasileira de pessoal altamente qualificado.

Analisando a imigração nos três censos (1991, 2000 e 2010) por região geográfica, percebe-se que, em valores absolutos, todas as regiões apresentaram um crescimento constante no número de imigrantes ao longo das três ultimas décadas. A participação percentual desses imigrantes sobre a população de mestres e doutores ampliouse em todas as regiões ao longo do período analisado - exceção feita ao Nordeste, durante a década de 90. A emigração também teve crescimento absoluto em todas as regiões do País.

Tabela 2. Taxa de crescimento anual da população total, população de graduados e pós-graduados (mestres e doutores) no Brasil (estados e regiões geográficas) - 1991 a 2010

\begin{tabular}{l|c|c|c|c|c|c}
\hline \multirow{2}{*}{ UF } & \multicolumn{2}{|c|}{ Tax Cres Pop Total } & \multicolumn{2}{c|}{ Tax Cres Grad } & \multicolumn{2}{c}{ Tax Cres Pós-Grad } \\
\cline { 2 - 7 } & $1991-2000$ & $\mathbf{2 0 0 0 - 2 0 1 0}$ & $\mathbf{1 9 9 1 - 2 0 0 0}$ & $\mathbf{2 0 0 0 - 2 0 1 0}$ & $\mathbf{1 9 9 1 - 2 0 0 0}$ & $\mathbf{2 0 0 0 - 2 0 1 0}$ \\
\hline AC & 3,28 & 3,09 & 4,56 & 12,56 & 8,33 & 10,79 \\
\hline AM & 3,30 & 2,39 & 3,46 & 11,59 & 11,06 & 8,40 \\
\hline AP & 5,72 & 3,84 & 4,75 & 14,54 & 16,47 & 15,00 \\
\hline PA & 2,53 & 2,27 & 3,14 & 8,48 & 7,38 & 8,50 \\
\hline RO & 2,22 & 1,38 & 2,75 & 12,03 & 7,19 & 10,41 \\
\hline RR & 4,54 & 3,72 & 4,97 & 12,81 & 0,52 & 15,47 \\
\hline TO & 2,61 & 2,00 & 9,10 & 15,46 & 15,74 & 13,44 \\
\hline
\end{tabular}




\begin{tabular}{|c|c|c|c|c|c|c|}
\hline \multirow{2}{*}{ UF } & \multicolumn{2}{|c|}{ Tax Cres Pop Total } & \multicolumn{2}{|c|}{ Tax Cres Grad } & \multicolumn{2}{|c|}{ Tax Cres Pós-Grad } \\
\hline & $1991-2000$ & $2000-2010$ & $1991-2000$ & $2000-2010$ & $1991-2000$ & $2000-2010$ \\
\hline NORTE & 2,85 & 2,32 & 3,77 & 10,92 & 8,62 & 9,57 \\
\hline$A L$ & 1,32 & 1,10 & 2,29 & 5,95 & 11,49 & 8,57 \\
\hline $\mathrm{BA}$ & 1,09 & 0,77 & 2,18 & 7,92 & 9,22 & 8,63 \\
\hline CE & 1,73 & 1,44 & 2,57 & 7,57 & 9,59 & 8,46 \\
\hline MA & 1,54 & 1,68 & 4,29 & 13,07 & 8,53 & 13,76 \\
\hline PB & 0,82 & 1,00 & 1,84 & 4,32 & 9,04 & 7,66 \\
\hline $\mathrm{PE}$ & 1,19 & 1,16 & 1,58 & 3,62 & 8,86 & 7,41 \\
\hline $\mathrm{Pl}$ & 1,08 & 1,03 & 3,58 & 12,14 & 6,79 & 11,33 \\
\hline RN & 1,57 & 1,47 & 2,89 & 6,82 & 7,59 & 10,29 \\
\hline SE & 2,01 & 1,65 & 1,90 & 9,46 & 13,30 & 10,14 \\
\hline NORDESTE & 1,31 & 1,18 & 2,24 & 6,96 & 9,15 & 8,79 \\
\hline ES & 1,96 & 1,41 & 3,32 & 7,23 & 9,69 & 10,02 \\
\hline MG & 1,44 & 1,01 & 2,73 & 6,12 & 8,26 & 8,43 \\
\hline $\mathrm{RJ}$ & 1,30 & 1,18 & 0,26 & 3,55 & 7,03 & 5,39 \\
\hline $\mathrm{SP}$ & 1,78 & 1,21 & 1,51 & 4,99 & 8,17 & 7,94 \\
\hline SUDESTE & 1,61 & 1,16 & 1,30 & 4,93 & 7,83 & 7,29 \\
\hline PR & 1,39 & 0,98 & 1,83 & 5,34 & 9,59 & 9,05 \\
\hline RS & 1,22 & 0,54 & 0,35 & 3,28 & 8,02 & 7,86 \\
\hline SC & 1,85 & 1,72 & 2,70 & 7,69 & 6,47 & 10,29 \\
\hline SUL & 1,41 & 0,97 & 1,30 & 4,98 & 8,20 & 8,80 \\
\hline DF & 2,79 & 2,54 & 2,74 & 5,70 & 7,32 & 8,99 \\
\hline GO & 2,47 & 2,04 & 2,98 & 9,53 & 9,63 & 10,19 \\
\hline MS & 0,28 & 1,84 & 6,03 & 6,76 & 11,26 & 10,36 \\
\hline MT & 3,87 & 2,15 & 1,23 & 9,01 & 6,59 & 10,06 \\
\hline CENTRO-OESTE & 2,37 & 2,12 & 3,07 & 7,67 & 8,13 & 9,56 \\
\hline Brasil & 1,63 & 1,30 & 1,61 & 5,67 & 8,10 & 7,99 \\
\hline
\end{tabular}

Fonte: FIBGE, Censos Demográficos de 1991 a 2010. Elaboração do autor.

Apesar dessa circulação crescente de entradas e saídas de pessoas altamente qualificadas nas regiões brasileiras, não se pode dizer que há uma circulação de cérebros no contexto nacional, pois as assimetrias no ensino superior brasileiro (graduação e pós-graduação) persistem entre regiões e estados. 

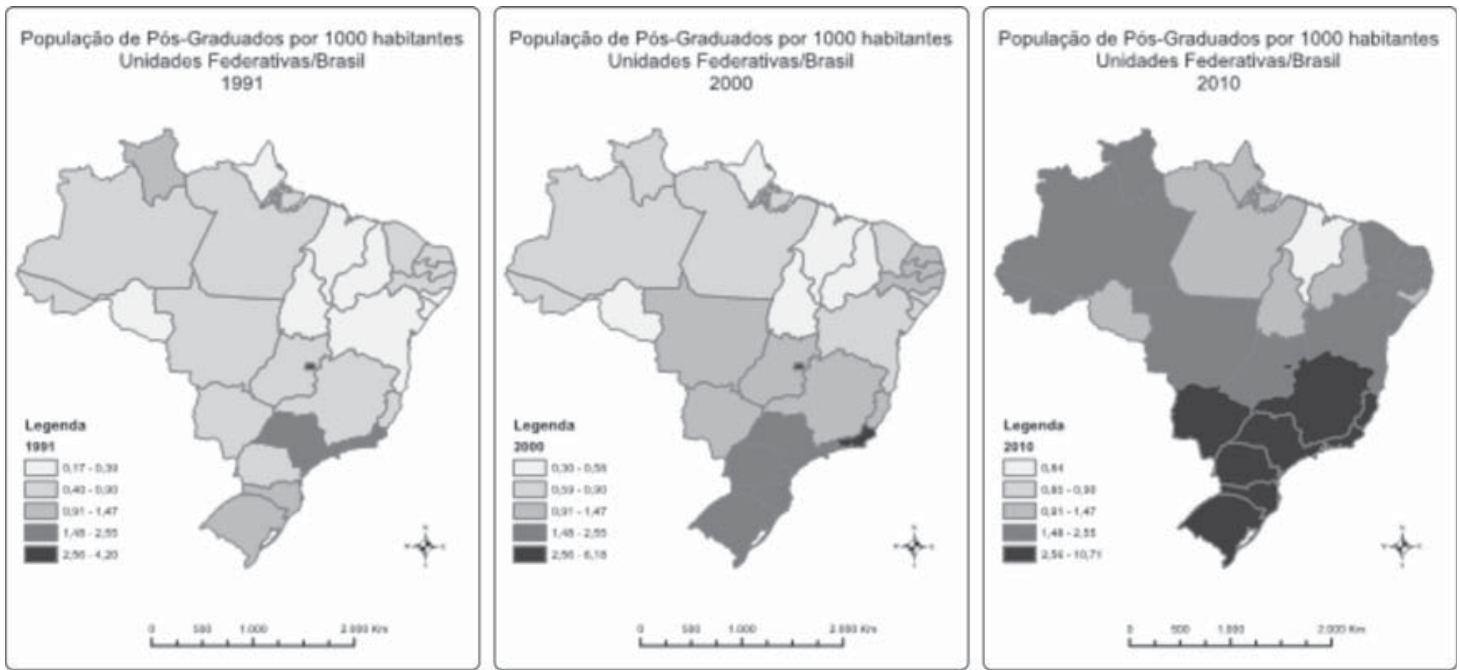

Fonte: FIBGE, Censos Demográficos de 1991 a 2010. Elaboração do autor.

\section{Figura 1. Cartograma da população de pós-graduados (mestres e doutores) no Brasil e estados por 1.000 habitantes (1991-2010)}

Para se confirmar tal afirmação, primeiramente se calculou o Índice de Eficácia Migratória (IEM) para os estados brasileiros e suas regiões geográficas ao longo das três últimas décadas. Como a migração de pessoas altamente qualificadas é uma modalidade migratória muito específica, para a elaboração deste trabalho, optou-se por readaptar as classificações propostas por Baeninger (1999).

Como essa modalidade migratória tem como característica uma participação percentual elevada na migração intrarregional, optou-se por calcular também o IEM entre as regiões, ou seja, foi incluída no cálculo desse novo IEM somente a migração inter-regional.

O Índice de Eficácia Migratória (IEM) mede a capacidade de atração, evasão ou rotatividade migratória e é obtido por meio da relação entre o saldo migratório e o volume total de migrantes (imigrantes mais emigrantes). Esse indicador permite a comparação entre os estados/ regiões, independentemente do volume absoluto da imigração e da emigração. 
Tabela 3. Classificação do Índice de Eficácia Migratória (IEM)

\begin{tabular}{l|l}
\hline Classes IEM & Classificação da potencialidade de absorção migratória \\
\hline$-0,10$ a $-0,40$ & Área de evasão de pessoal qualificado \\
\hline 0,09 a $-0,09$ & Área de rotatividade migratória \\
\hline 0,30 a 0,10 & Área de absorção de pessoal qualificado \\
\hline
\end{tabular}

Fonte: Elaboração do autor.

Atendendo aos pressupostos do Brain Circulation, espera-se que as regiões geográficas que compõem o Brasil venham a ser classificadas como área de rotatividade migratória. Esse processo tenderá a ser mais rápido quanto mais intensas forem a criação e/ou a expansão do sistema nacional de pós-graduação e também a implantação de instituições de ensino superior (IES) nos estados menos desenvolvidos do País, especialmente universidades públicas, pois elas têm um percentual maior de mestres e doutores em seu quadro de docentes vis-à-vis as IES privadas.

Infelizmente, a recomendação de redução das assimetrias entre as regiões brasileiras proposta no Plano Nacional de Pós-Graduação tem evoluído de forma lenta. No ano de 2000, as regiões Norte, Nordeste e Centro-Oeste tinham $2,1 \%, 14,2 \%$ e $5,4 \%$, respectivamente, dos programas de pós-graduação reconhecidos e recomendados pela Capes, contudo cinco estados do Norte não tinham nenhum programa de pós-graduação instalado, e, no Nordeste, os estados do Piauí e de Sergipe contavam com apenas dois programas de pós-graduação cada um, de acordo com os dados disponibilizados pelo GeoCapes².

Em 2010, o número de programas de pós-graduação dessas regiões apresentou crescimento. A participação percentual conjunta dessas três regiões passou de 21,8\%, em 2000, para 31,8\%, em 2010, e, agora, todos os estados da Federação contam com pelo menos um programa de pós-graduação.

2 GeoCapes é uma ferramenta de dados georreferencial mantida pela Capes.
A Tabela 4 apresenta o IEM para todos os estados e regiões brasileiras entre os anos de 1991 e 2010. Analisando os dados das regiões, a partir do ano de 1991, pode-se notar que, exceto o Centro- 
Oeste, que foi classificado como área de absorção, todas as demais regiões foram classificadas como área de rotatividade migratória, ou seja, independentemente do volume, há um equilíbrio entre entradas e saídas de mestres e doutores. Em 2000, a região Norte passa a ser classificada como área de absorção migratória (há um ganho líquido de mestres e doutores), mesma classificação do Centro-Oeste. As demais regiões permaneceram como áreas de rotatividade migratória. As classificações das regiões não se alteraram no Censo de 2010.

Analisando o IEM dos principais estados formadores e contratantes de mestres e doutores, começando por São Paulo, nos Censos de 1991 a 2010, nota-se que esse estado foi classificado como área de rotatividade migratória. No Censo de 2000, São Paulo passou a ser considerado como área de evasão migratória. Uma hipótese para essa mudança no IEM paulista pode estar associada à oferta e à demanda no mercado de trabalho de pessoal altamente qualificado.

Como já ressaltado, os principais contratantes desse grupo populacional são instituições de ensino, principalmente as vinculadas ao ensino superior (privadas e, especialmente, públicas), administração pública, instituições científicas e tecnológicas e empresas (estatais e privadas).

Para Pochmann (2008), entre 1990 e 2004, o emprego público, como proporção da População Economicamente Ativa (PEA)', caiu 14,2\%, retornando assim, ao final desse período, à posição relativa que o País possuía na década de 70. A proporção do emprego público em relação à população total caiu $6,1 \%$ nesse período.

No mesmo período, paralelamente à menor expansão das vagas no setor público, o mercado de trabalho para pessoas com diploma universitário apresentou uma forte queda. Em 2004, a taxa de desemprego do trabalhador de nível universitário foi $25 \%$ superior à de 1995, conclui Pochmann (2008).

O mercado de trabalho mais restritivo, conforme já destacado, associado a uma crescente oferta (alunos titulados) de mestres e 
doutores no principal estado componente do SNPG, pode ter estimulado o aumento da evasão de mestres e doutores formados em São Paulo para outras unidades da Federação, em busca de melhores oportunidades de trabalho.

O IEM do Rio de Janeiro e o do Rio Grande do Sul apresentaram o mesmo comportamento ao longo do período analisado. Na década de 80, esses estados eram considerados como áreas de evasão migratória, nas duas décadas seguintes, porém, passaram a ser considerados como áreas de rotatividade migratória.

A saída de mestres e doutores do Rio de Janeiro para outras regiões pode estar associada à transferência da Capital Federal para Brasília e à perda do dinamismo econômico do estado fluminense hipótese levantada por Guimarães (2002) e confirmada pelos dados do Censo 1991.

Analisando somente os dados da Tabela 5, podemos concluir que o Brasil está evoluindo rapidamente para ser classificado como zona de circulação de cérebros. Apesar de reconhecermos que as trocas migratórias entre estados e regiões vêm se acentuando ao longo desse período, ainda persistem as profundas assimetrias entre estados e regiões, que tanto caracterizam o desenvolvimento nacional.

Esse aumento na mobilidade de mestres e doutores ocorreu principalmente nas trocas intrarregionais. Na década de 80 , elas eram responsáveis por $63 \%$ do total da migração interna de mestres e doutores. Nos anos 90, esse percentual subiu para 67\%, e, no Censo de 2010, atingiu a cifra de $75 \%$.

Em artigo de 2002, Guimarães conclui que os deslocamentos de longa distância (inter-regional) são realizados, majoritariamente, por pesquisadores que visam complementar a sua formação acadêmica e profissional, enquanto as mudanças de curta distância (intrarregional) são efetuadas em sua maioria por cientistas que vão assumir novos postos de trabalhos. 
妾

응

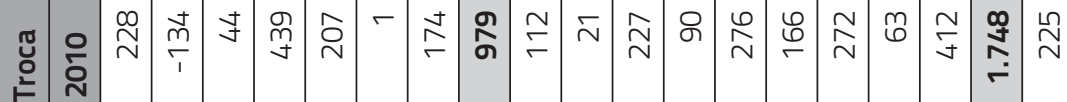

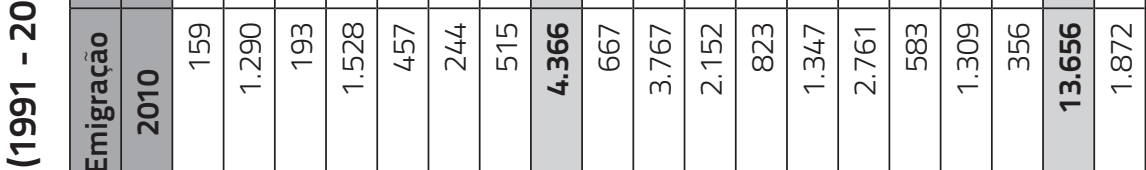

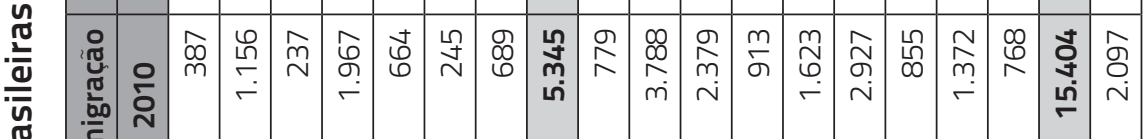

는

产

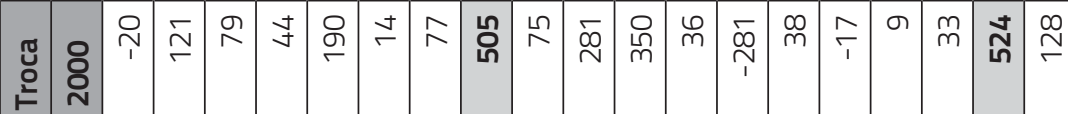

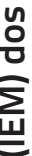

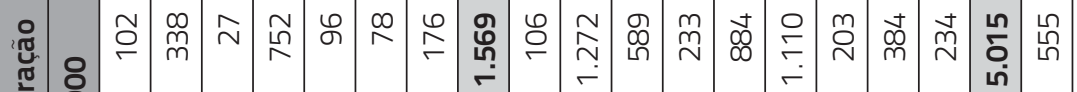

แ

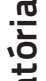

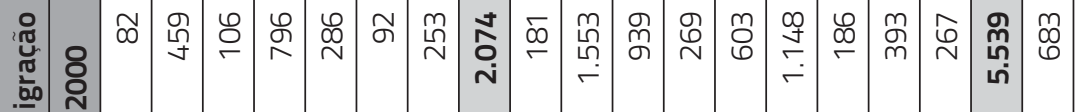

है

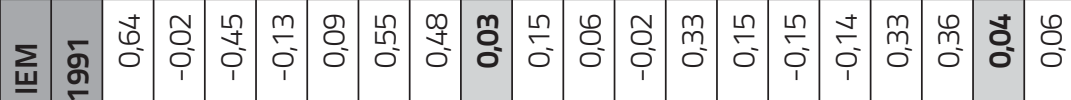

๘ூ

운

空

i

兽

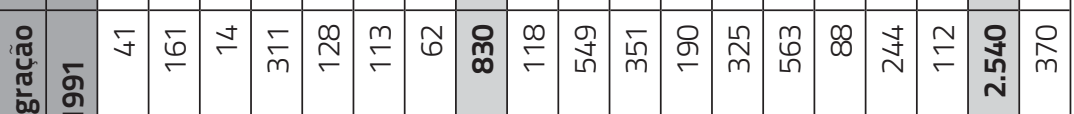
$\underline{\underline{E}}$

$\underline{\underline{E}}$

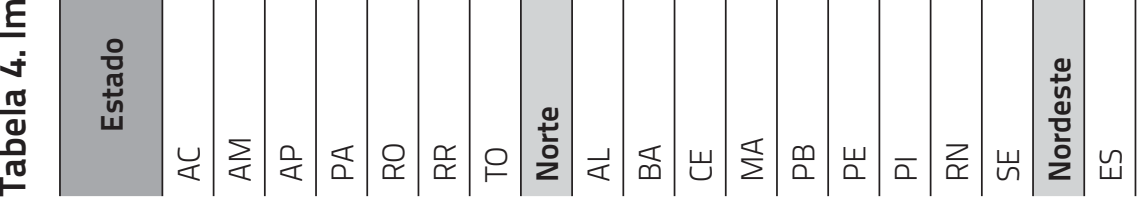




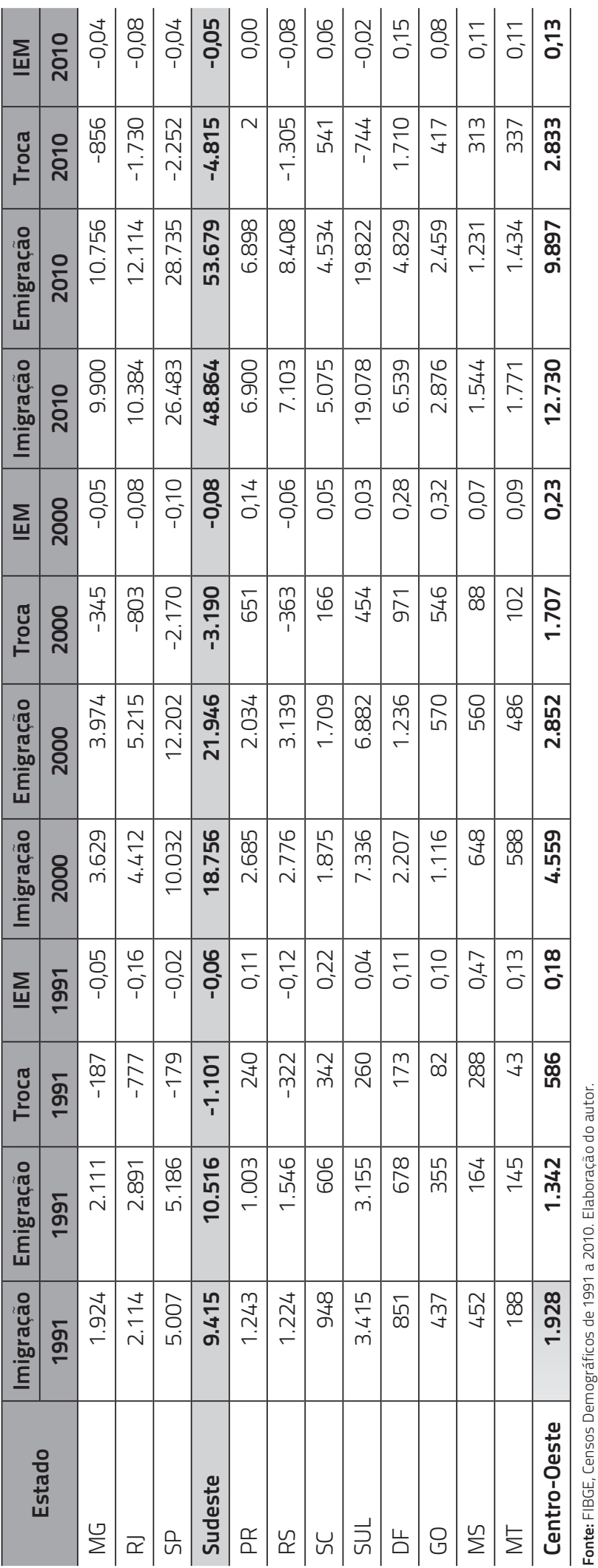


Complementando o argumento anterior, Rigotti (2006) observa que

\begin{abstract}
Ao que parece, o Nordeste tem adquirido maior autonomia quando se trata de fluxos de pessoas mais escolarizadas e/ou as regiões que the ofereciam trabalhadores qualificados já não desempenham o mesmo papel.

Essa tendência à regionalização também foi observada em relação ao Centro-Oeste, que, à semelhança do que ocorreu em relação ao Rio de Janeiro e o Nordeste, também experimentou um enfraquecimento de sua interação com a mesorregião da Área Metropolitana de São Paulo (p. 250).
\end{abstract}

O crescimento da migração intrarregional, associado ao aumento do número de alunos titulados entre 2000 e 2010 nas próprias regiões (em especial no Norte e no Centro-Oeste), corrobora o argumento dos autores citados nesta pesquisa. Apesar de serem necessários estudos mais detalhados sobre esse tema, os dados obtidos para a elaboração deste trabalho reforçam a tese de que a mudança de domicílio de curta distância (intrarregional) tende a ser realizada por mestres e doutores quando estes vão assumir um novo emprego.

A migração de longa distância, apesar de apresentar redução percentual sobre o total dos migrantes com título de mestres e doutores no Brasil, manteve crescimento em termos absolutos ao longo do tempo. 0 volume de migrantes vem dobrando de tamanho a cada dez anos. No Censo de 1991, aproximadamente 6,6 mil pessoas mudaram de residência; no Censo de 2010, esse número tinha atingido a cifra de 25,4 mil pessoas. Se aceitarmos a hipótese sugerida por Guimarães (2002) de que migrações de longa distância são realizadas, em sua grande maioria, por pesquisadores em busca de complementação de sua formação, poderemos concluir que, mesmo tendo ocorrido uma expansão no sistema nacional de pós-graduação em direção às regiões menos desenvolvidas do País (Norte, Nordeste e Centro-Oeste), ainda assim, elas mantêm dependência com relação às regiões Sul e Sudeste para formar quadros profissionais mais qualificados.

A Tabela 5 apresenta os fluxos migratórios entre as regiões e seus respectivos IEM. Ao longo das três últimas décadas, o Sudeste, em 
relação às demais regiões do País (com a exceção da região Norte, no Censo de 1991), foi classificado como área de evasão migratória. Como essa região concentrou $60 \%$ e $49 \%$ dos programas de pós-graduação nacionais em 2000 e 2010, respectivamente, é esperado que ela mantenha o posto de fornecedora de mão de obra qualificada para as demais regiões do País.

Entretanto, dois pontos chamam a atenção. O primeiro é o ritmo de crescimento anual nas trocas (imigração menos emigração) entre o Sudeste e as demais regiões. De acordo com o Censo 1991/2000, essas trocas cresceram a uma taxa de $12,5 \%$ ao ano; no período seguinte, 2000/2010, essa taxa apresentou crescimento de 4,6\%, ou seja, de apenas um terço da taxa do período anterior. Esse ritmo menor de expansão pode ser explicado pelo movimento de desconcentração do SNPG em direção às demais regiões do País, hipótese confirmada por Sabbadini e Azzoni (2006). Concluem os referidos autores que os estados com mais programas de pós-graduação tendem a receber menos migrantes altamente qualificados.

O segundo ponto é o IEM entre o Sudeste e o Norte na década de 80 . Segundo o Censo de 1991, o Norte fora classificado como área de rotatividade migratória, uma possível explicação para isso pode ser a baixa demanda por profissionais com título de mestrado e doutorado pela região nos anos 80. Em 1998 (ano de início da série disponível no siteGeoCapes/Capes), existiam apenas 21 programas de pós-graduação (1,6 \% do total) reconhecidos e recomendados pela Capes na região, instalados em dois estados apenas (Amazonas e Pará). Provavelmente essa assimetria entre as regiões era bem mais acentuada na década de 80, o que acabou gerando uma demanda restritiva no Norte por pessoas com o título de mestre e doutor.

O Sul, por ser a segunda região com mais programas de pósgraduação no País (21\% do total em 2010, segundo a Capes), tem o papel complementar de formação e de fornecimento de mão de obra qualificada para as regiões Nordeste, Centro-Oeste e Norte. O IEM da região Sul/Norte na década de 80 identificou o Sul como área de rotatividade migratória; nas duas décadas seguintes, essa classificação foi alterada para área de evasão migratória. 


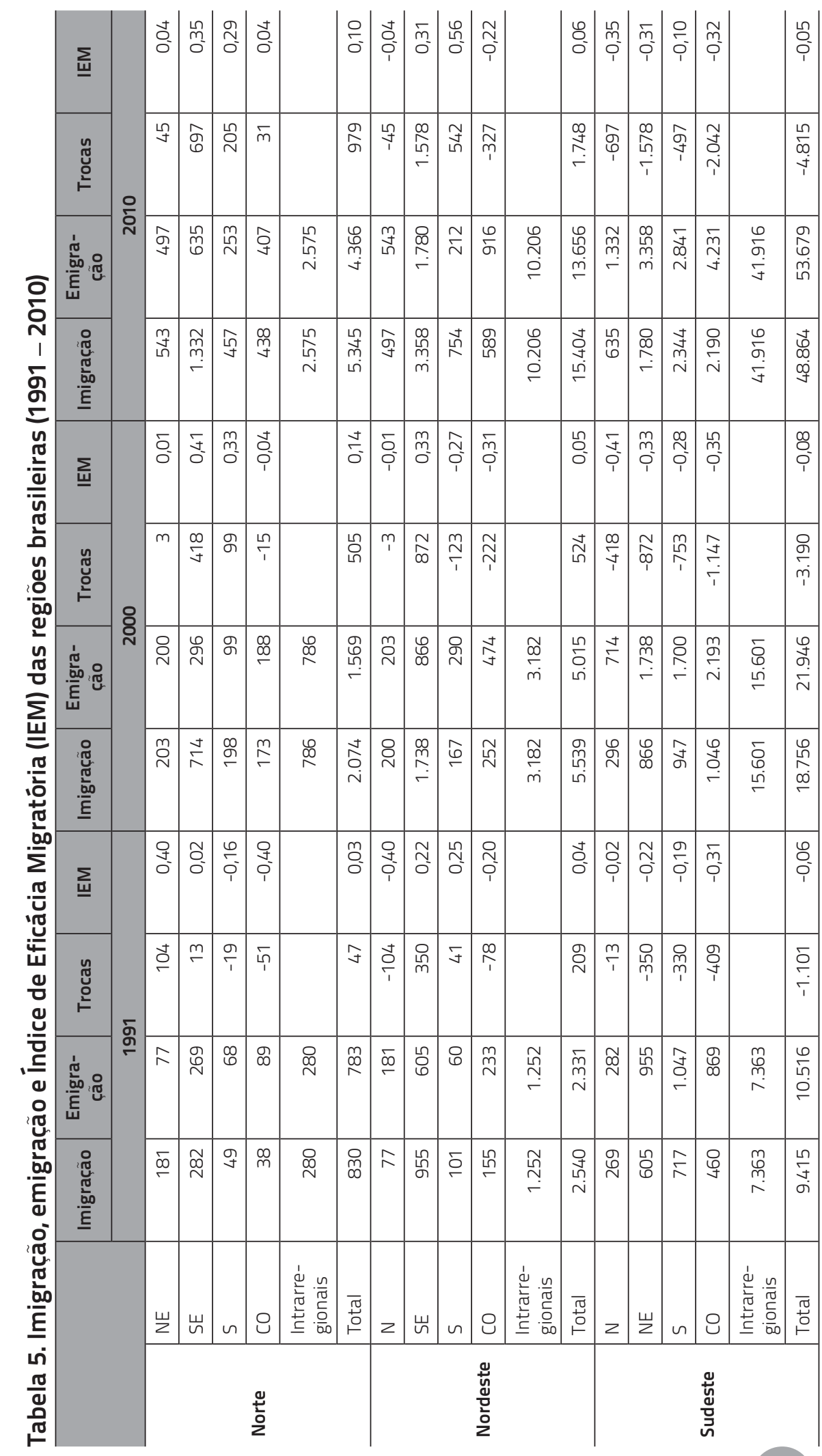

in: 


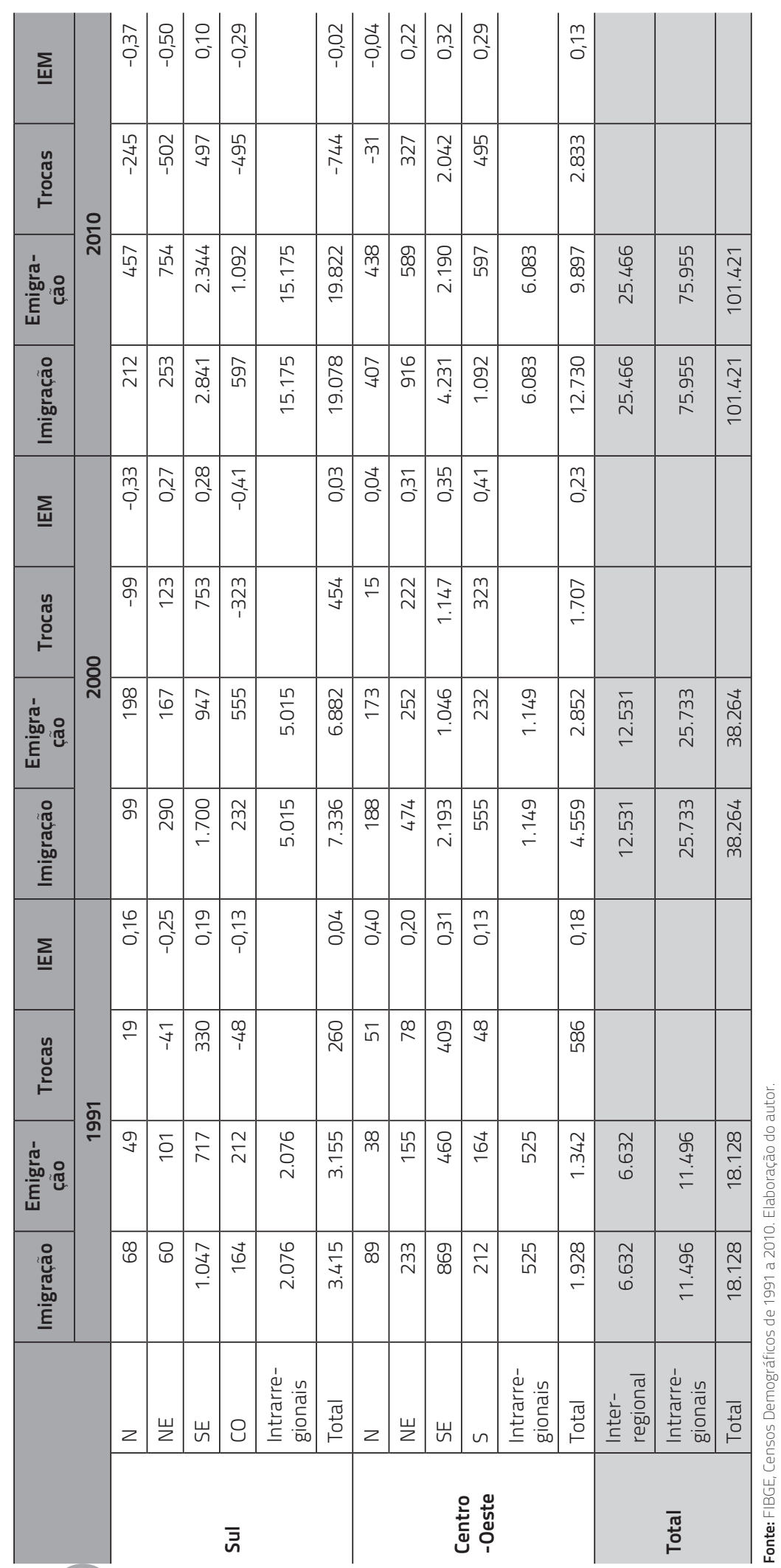


O IEM da região Sul, em relação ao Centro-Oeste, classifica essa região com área de evasão migratória. Guimarães (2002) questionou se o processo de expansão da fronteira agrícola desde o Rio Grande do Sul, passando pela região Centro-Oeste e chegando ao Norte, teria ficado restrito à migração de trabalhadores rurais e pequenos proprietários ou se, em face desse componente, teria estabelecido laços societais mais complexos e permanentes com essas regiões, implicando, entre outros aspectos, a mobilidade de pesquisadores entre elas. Os dados apresentados na Tabela 6 não deixam dúvida de que houve o estabelecimento de um fluxo de mestres e doutores para as regiões Centro-Oeste e Norte proveniente do Sul do País e mostram que, ao longo do tempo, ocorreu um aumento expressivo no volume das trocas migratórias.

A região Nordeste (área de evasão), segundo o IEM, forneceu mão de obra qualificada (mestres e doutores) para a região Centro-Oeste ao longo das três décadas analisadas. A interação do Nordeste com a região Norte é um pouco mais dinâmica. Na década de 80 , a região Nordeste era a principal ofertante de mestres e doutores para o Norte, superando inclusive as regiões Sudeste e Sul do País. Possivelmente, esse fato está associado à proximidade geográfica entre elas.

Nas duas décadas seguintes, o Nordeste passa a ser classificado como área de rotatividade migratória em relação ao Norte do País. Apesar de serem necessárias mais informações para entender essa mudança de classificação entre as duas regiões (o que foge ao escopo deste trabalho), é possivel levantar algumas hipóteses para esse movimento. A primeira delas pode estar associada ao crescimento absoluto e à maior diversificação dos programas de pós-graduação no Nordeste vis-à-vis a região Norte. Esse fato, associado à menor distância entre essas duas regiões, sobretudo quando comparadas as distâncias com o Sudeste e com o Sul, pode ter estimulado a maior imigração de nortistas em direção aos estados nordestinos em busca de complementação de sua formação acadêmica. Outra explicação para esse movimento pode estar vinculada ao maior dinamismo da economia nordestina nos últimos anos. 
Em relação às demais regiões, o Norte e o Centro-Oeste foram classificados como áreas de absorção migratória (exceção feita para a região Norte no Censo 1991) ao longo dos três últimos censos. Vale a pena destacar também que o volume de trocas migratórias destas duas regiões com o restante do Brasil teve uma variação percentual elevada entre as décadas de 80 e 90 (249\%) e de apenas 72\% entre os Censos de 2000 e 2010.

\section{Considerações finais}

As informações trazidas pelos três últimos censos confirmam que a desconcentração do sistema de formação dos mestres e doutores em direção às regiões menos desenvolvidas do País promoveu um aumento da migração intrarregional, porém a migração inter-regional cresceu em termos absolutos, o que demonstra que a mobilidade dos mestres e doutores entre os demais estados e regiões mantém a assimetria com o Sudeste e com o Sul, sendo estas regiões as principais fornecedoras de mão de obra para o restante do País. Em razão desse cenário de assimetria na migração de mestres e doutores em âmbito nacional ao longo das últimas décadas, não é possível afirmar que há no Brasil um movimento de circulação de cérebros.

\section{Nota explicativa}

i Compreende o potencial de mão de obra com que pode contar o setor produtivo, isto é, a população ocupada e a população desocupada, assim definidas: população ocupada - pessoas que, em um determinado período de referência, trabalharam ou tinham trabalho, mas não trabalharam (por exemplo, porque estavam em férias). População desocupada - pessoas que não tinham trabalho em um determinado período de referência, mas estavam dispostas a trabalhar e, para isso, tomaram alguma providência efetiva (por exemplo, consultando pessoas, jornais etc.).

Recebido em 27/11/2013

Aprovado em 09/07/2014 


\section{Referências}

BAENINGER, R. A. As fases e faces da migração em São Paulo. Campinas: Núcleo de Estudos de População - Nepo/Unicamp, 2012.

Região, Metrópole e Interior: espaços ganhadores e espaços perdedores nas migrações recentes, Brasil: 1980-1996. Textos Nepo, v. 35, 1999.

CUNHA, L. A. C. R. A pós-graduação no Brasil: função técnica e função social. Revista de Administração de Empresas, São Paulo, v. 14, n. 5, out. 1974.

CURY, C. R. J. Quadragésimo ano do parecer CFE n 977/65. Revista Brasileira de Educação, Rio de Janeiro, n. 30, dez. 2005.

DAUGELIENE, R.; MARCINKEVICIENE, R. Brain Circulation: Theoretical Considerations. Inzinerine Ekonomika-Engineering Economics, v. 3, p. 49-57, 2009.

GUIMARÃES, R. A diáspora: um estudo exploratório sobre o deslocamento geográfico de pesquisadores brasileiros na década de 90. Rio de Janeiro: Instituto Universitário de Pesquisa do Rio de Janeiro, 2002.

MUKKALA, K. Knowledge spillovers - mobility of highly educated workers within high technology sector in Finland. In: ERSA conference papers. European Regional Science Association, 2005.

POCHMANN, M. O emprego no desenvolvimento da nação. São Paulo: Boitempo Editorial, 2008.

RIGOTTI, J. I. R. Geografia dos fluxos populacionais segundo niveis de escolaridade dos migrantes. Estudos Avançados, v. 20, n. 57, p. 237$254,2006$.

SABBADINI, R.; AZZONI, C. R. Migração interestadual de pessoal altamente educado: evidências sobre a fuga de cérebros. Encontro Nacional de Economia, v. 34, n. 5, 2006. 
VIOTTI, E. B. Doutores 2010: Estudos da demografia da base técnicocientífica brasileira. Brasília: Centro de Gestão e Estudos Estratégicos (CGEE), 2010.

. Mestres 2012: Estudos da demografia da base técnico-científica brasileira. Brasília: Centro de Gestão e Estudos Estratégicos (CGEE), 2012. 


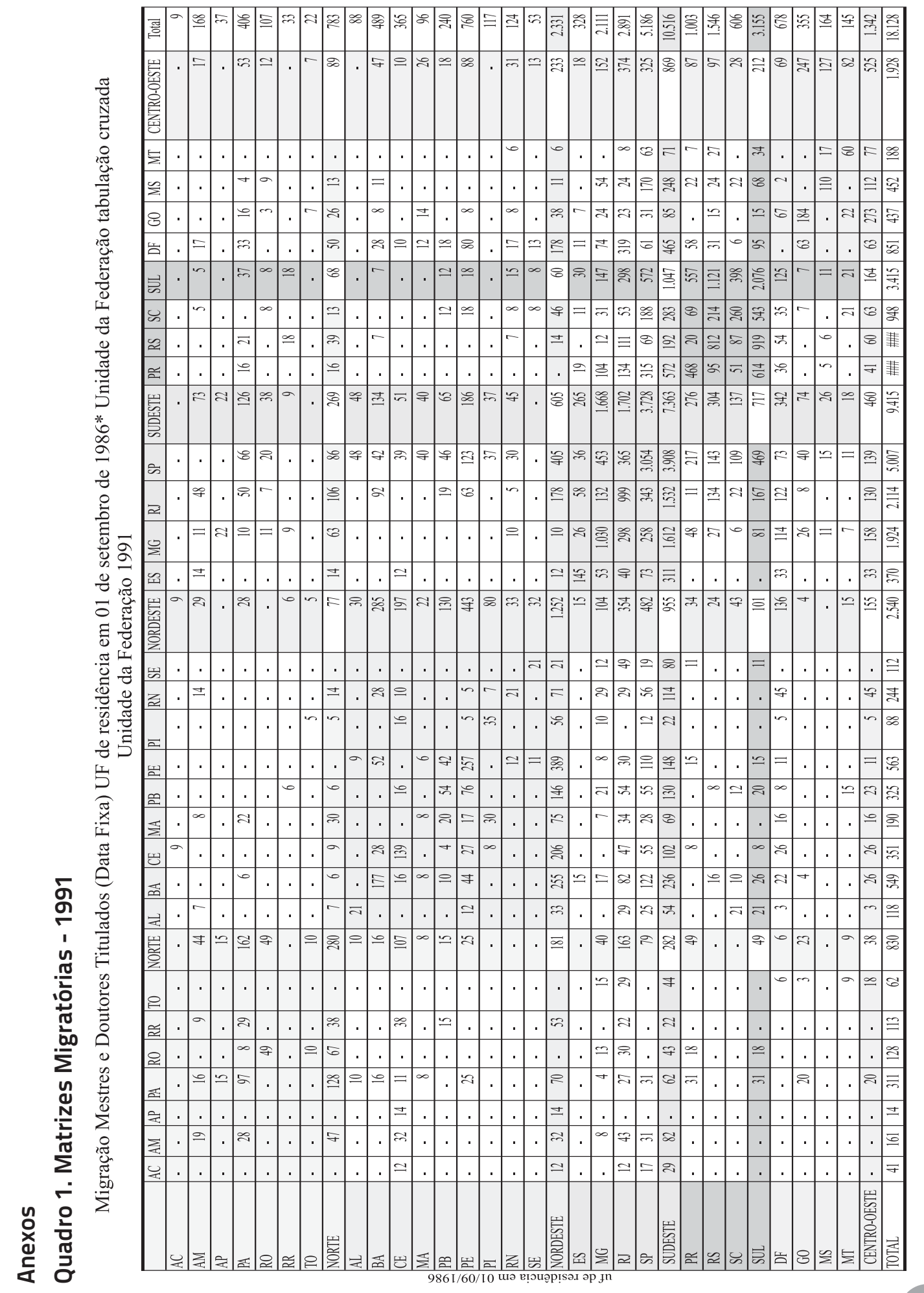




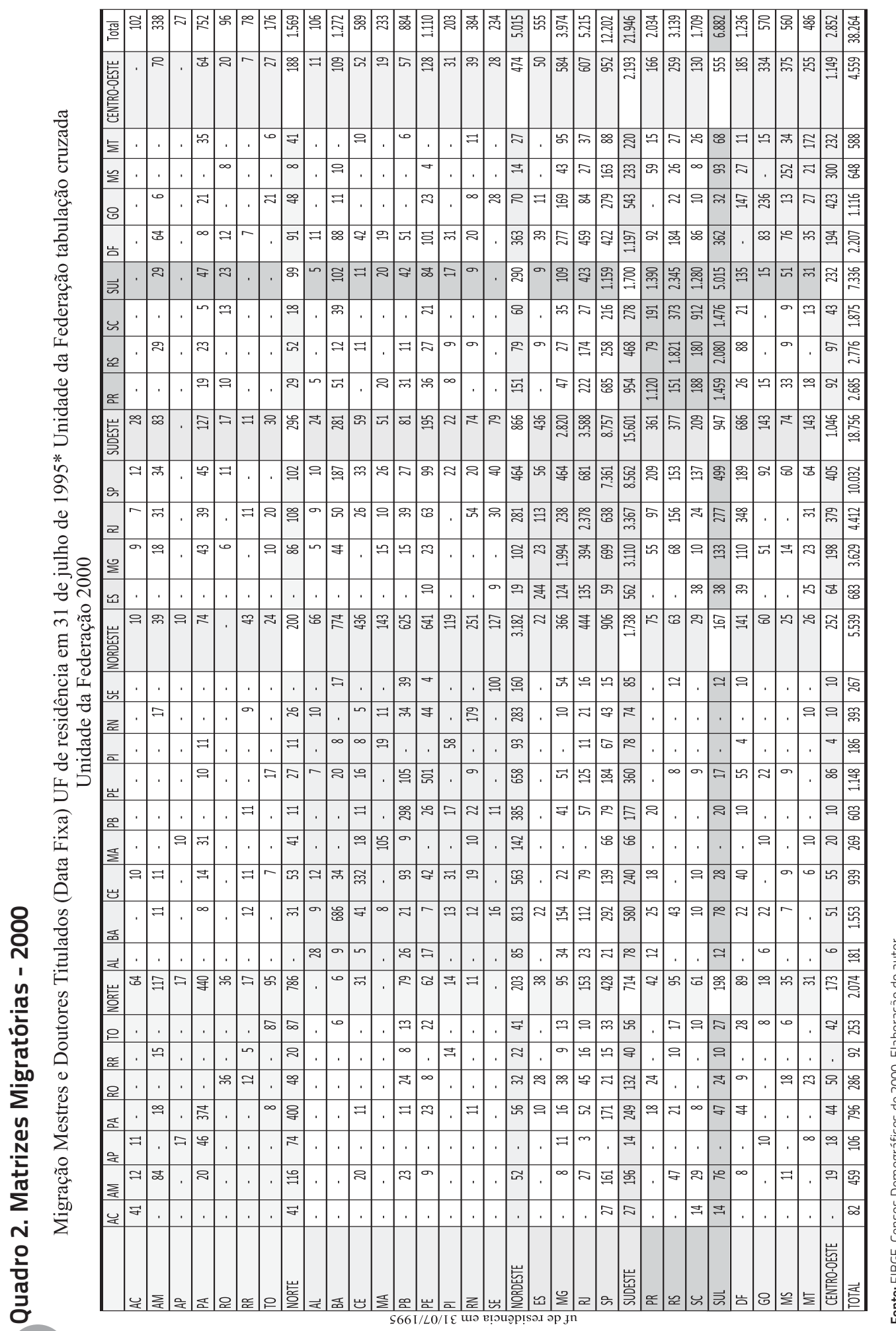




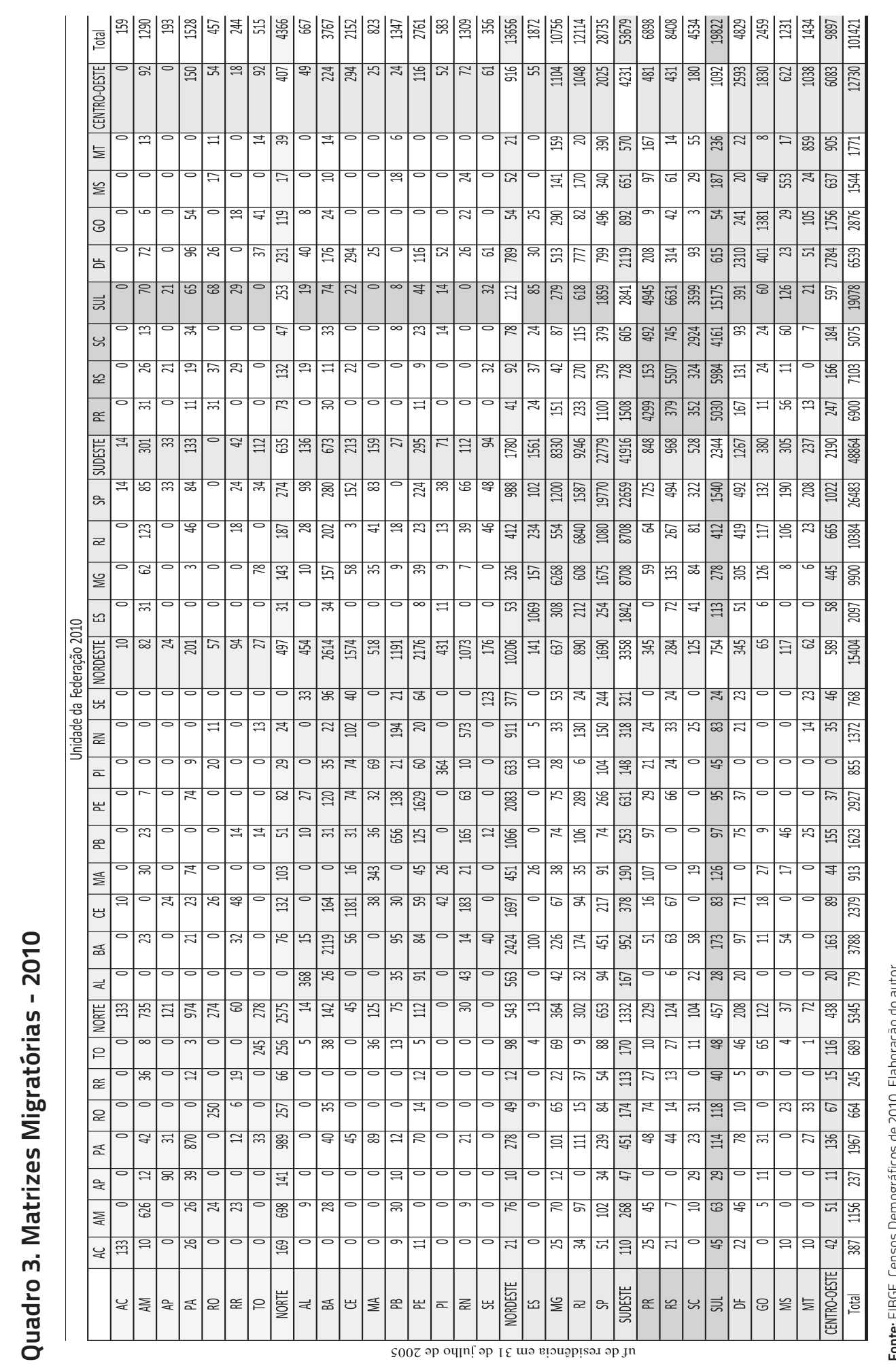

